\title{
Traducción
}

\section{La escuela como práctica y tecnología de la pertenencia al mundo '}

Jan Masschelein

Laboratory for Education and Society

Agradezco la invitación y la oportunidad de formular algunas reflexiones acerca de la relación entre la escuela y la pertenencia, a partir del libro escrito junto con mi colega Maarten Simons: Defensa de la escuela. Una cuestión pública, el cual pueden descargar de internet de forma gratuita. Con el fin de señalar cómo nos enfrentamos hoy con una desescolarización y cómo esta afecta el asunto de la pertenencia, primero indicaré cómo concibo la escuela. Quiero investigar la relación entre la escuela y la pertenencia desde un punto de vista educativo. Esto quiere decir que no preguntaré

1 Este es el texto de una lección inaugural realizada en la Conferencia Internacional: "El poder de la pertenencia" el 11 de octubre de 2018 en Vester Skerninge, Dinamarca - organizada por la Independent Academy for Free School Teaching-. Este es el texto del que se ha dicho que solo hay algunas referencias. El texto se basa en parte en otros dos textos: Masschelein y Simons $(2014,2019)$. Aquí se presenta la traducción y revisión del inglés al español de Brayan Andrés Morantes Martinez - Universidad de Boyacá- y Juan Guillermo Díaz Bernal — Universidad Pedagógica y Tecnológica de Colombia-. 
cómo la escuela podría promover el poder de la pertenencia, lo cual exigiría que yo primero explore y articule qué es la pertenencia y qué puede lograr. Por supuesto, tal iniciativa es legítima, sin embargo, implica que la escuela misma está planteada de una forma instrumental. Como Dewey (2004) lo plantea, la escuela aparece en primera instancia como un intento de

dar forma a las disposiciones y creencias de sus miembros. Incluso cuando el proceso de la educación no apunta a la intacta perpetuación de las instituciones existentes, se asume que debe haber una imagen mental de algún fin deseado, personal $y$ social, el cual se debe alcanzar, y que esta concepción de un fin fijo determinado debería controlar los procesos educativos. Los reformadores comparten esta convicción con los conservadores. Los discípulos de Lenin y Mussolini compiten con los capitanes de la sociedad capitalista con la intención de propiciar una formación de disposiciones e ideas, las cuales conduzcan a una meta preconcebida... Un método social experimental probablemente se manifestaría, primero que todo, al renunciar a esta noción (pp. 200-201).

Tal visión experimental también podría ser llamada externa y es de hecho muy común. Los enfoques sociológicos, psicológicos, fisiológicos, éticos y políticos de la escuela parten de algo que está articulado independientemente de la educación escolar y preguntan cómo la escuela puede ser instrumental o nociva para realizar funciones -socialización, cualificación, selección-, para mejorar procesos - la perspectiva psicosocial implica que existen procesos de desarrollo cognitivo, emocional y moral que pueden ser definidos y descritos como independientes de la escuela y que, por lo tanto, esta puede facilitar o dificultar dichos procesos-, con el fin de alcanzar los ideales -ideas conservadoras o progresistas del educando-. No quiero cuestionar estos enfoques - son muy valiosos-, pero quiero hacer el movimiento inverso: trataré de adoptar una perspectiva interna e intentaré articular qué es la escuela como una forma pedagógica y qué hace, cómo opera, si verdaderamente funciona como escuela - lo que a menudo no es el caso-. A partir de eso, elaboraré una comprensión escolástica de la pertenencia. Ciertamente, argumentaré que, como forma pedagógica, la escuela es en sí misma una práctica particular y una tecnología de la pertenencia, pero ahora nos enfrentamos con ambientes de aprendizaje que incluyen muchas operaciones de 
desescolarización, y por lo tanto afectan la pertenencia. Concluiré que para fomentar la pertenencia necesitamos reinstaurar más la escuela en nuestras instituciones educativas.

Comenzaré con una pequeña descripción:

Ella ha visto estos animales muchas veces. A algunos los conoce por su nombre. El gato y el perro, claro: pululan por la casa. También conoce a los pájaros. Podría distinguir a un gorrión de un herrerillo y a un mirlo de un cuervo, y, por supuesto, los animales de granja. Nunca pensó mucho en ello. Era simplemente así. Todos los de su edad sabían estas cosas. Era de sentido común, hasta ese momento. Una lección solo con grabados. Ni fotografías, ni películas. Hermosos grabados que convertían la clase en un zoológico, salvo que no había jaulas ni barrotes. Y la voz de la profesora que pedía nuestra atención porque dejaba hablar a los grabados. Los pájaros tienen pico y el pico una forma, y la forma revelaba el tipo de alimentación: comedores de insectos, de semillas, de pescado... Se sumergió en el mundo animal, que se tornó real. Lo que una vez le pareció obvio se le hizo extraño y seductor. Los pájaros hablaron de nuevo, y de pronto ella pudo hablar de ellos de otra forma. Que algunos pájaros emigran y otros se quedan. Que el kiwi es un pájaro, un pájaro sin alas de Nueva Zelanda. Que los pájaros pueden extinguirse. Le presentaron al dodó. $Y$ todo esto en una clase, con la puerta cerrada, sentada en su pupitre. Un mundo que no conocía. Un mundo al que nunca había prestado mucha atención. Un mundo que surgía como de la nada, invocado por los mágicos grabados y por una voz hechizante. No sabía qué la sorprendía más: este nuevo mundo que le había sido revelado o el creciente interés que descubría en sí misma. No importaba. Caminando a casa aquel día, algo había cambiado. Ella había cambiado (Masschelein \& Simons, 2014, p. 20).

La escuela como una forma pedagógica - no como una forma institucional, que por lo tanto puede encontrarse también afuera de la institución- puede ser concebida como una recopilación particular - artificial, tecnológica y pedagógicamente- compuesta -unión- y como organización de personas, tiempo, espacio e intereses que constituye un medio en el que las personas jóvenes- son llevadas en compañía de otros y en compañía de algo del mundo de una manera particular, para que el mundo se abra y para que uno empiece a pertenecerle al mundo - no en un 
primer momento a la comunidad o la identidad-. Esto permite una forma particular de aprendizaje y experiencia que se aparta de la libertad, la igualdad y la ausencia de un destino preconcebido, natural o social. La escuela, en este sentido y del mismo modo que la democracia, es una invención por medio de la cual las anteriores generaciones se encargan de forma particular - una que es diferente de la socialización y la iniciación- de las nuevas generaciones y, como tal, no tiene realmente nada que ver con el tipo de aprendizaje natural o informal que es a menudo -implícita o explícitamentevalorado por aquellos que se oponen a las formas de aprendizaje "escolásticas".

La escuela como forma pedagógica es la reunión que hace que el tiempo libre suceda - por medio de todo tipo de tecnología y arquitectura, incluyendo también cierto espíritu docente-. Por lo tanto, la escuela en ese sentido existe como un evento - puede suceder, como puede que no-. El primer significado de la scholè griega, que es el origen del término escuela en muchas lenguas, se refiere al tipo de tiempo: tiempo libre como el tiempo que se separa del tiempo de producción - el tiempo tanto del hogar, oikos, y la sociedad, polis-. En la frase de Arendt (2016), la escuela es el momento "en el cual somos libres para el mundo"; es hora de estudiar y hacer ejercicio. Es vista como el tiempo para que las nuevas generaciones encuentren y formen - ino escojan! - su propio destino - el cual no es el definido, el proyectado o el soñado por las generaciones pasadas-, lo cual se puedellamar libertad pedagógica; y para estar en forma para cuidar el mundo común. Esa es la razón por la cual no solo se trata de socialización o iniciación, sino también de educación, porque implica la posibilidad de renovación. Por lo tanto, no se trata de vigilar - mantener o instalar el orden- o curar/ sanar. La escuela como una forma pedagógica no está orientada ni dominada por una utopía política ni por un ideal normativo de una persona, sino que es en sí misma la materialización de una creencia utópica. La fórmula de la escuela se puede resumir como: todo el mundo puede aprender cualquier cosa. Dicho de otra manera, ni lo que puedes ni tienes que aprender es "naturalmente" predefinido. No hay una conexión "predefinida" entre las habilidades de un cuerpo y las posiciones sociales. iNo sabemos de lo que es capaz un cuerpo o una mente! Esto significa que la escuela desde un principio fue un ataque a la idea de que solo la aristocracia tiene "tiempo 
libre" - los demás deben trabajar- y a la contundente fábula que Platón cuenta en sus reflexiones sobre el "estado ideal":

La historia cuenta que, érase una vez, la madre naturaleza inventó a todos los seres humanos y mezcló diferentes metales -oro, plata, bronce y hierro- en sus personajes [...] Sois, pues, hermanos todos cuantos habitáis en la ciudad [...] pero, al formaros, los dioses hicieron entrar oro en la composición de cuantos de vosotros están capacitados para mandar, por lo cual valen más que ninguno; plata, en la de los auxiliadores, y bronce y hierro, en la de los labradores y demás artesanos (1992, p. 415).

La escuela desde sus principios fue un ataque a esta fábula. Su fórmula está basada en la frase pedagógica por excelencia: "solo intenta, solo inténtalo tú también” -igualdad pedagógica-.

Sin embargo, una condición de tiempo libre no es un lugar de vacío, sino una condición en la que las cosas - palabras y prácticas- están desconectadas de su uso regular - en la familia y en la sociedad-y, por lo tanto, se refiere a una condición en la que algo del mundo está abierto al uso común. Libre, entonces, tiene un significado positivo y negativo: libre del tiempo y el espacio productivos - se suspende la lógica de la ganancia o restitución económica o social-, pero libres de estudiar y hacer ejercicio para constituirse a sí mismo y estar en buena forma. Este es el doble sentido de lo que podríamos llamar formación.

Las operaciones de la escuela como forma pedagógica ${ }^{2}$ pueden resumirse de la siguiente manera:

1) Esta reunión y disposición particular suspende - pone fuera de servicio temporalmente, mas no destruye- los lazos de la familia y el Estado: cuando se entra a la escuela, todos se vuelven estudiantes o alumnos como los demás - dejan de ser hijo o hija-. Por lo tanto, es la marca visible de nuestra confirmación de que "nuestros" hijos no son "nuestros" hijos. Es importante enfatizar que la escuela es una performatividad plural e incorporada, dirigida a todos como solo uno, singular, todos estudiantes, lo cual no se basa en reconocer que cada

2 Véase también Larrosa (2018) y, especialmente, las contribuciones de Inés Dussel, Walter Kohan y Maximiliano López. 
persona tiene su propiedad o propiedades personales, sus talentos y necesidades propias. Se trata más bien de rechazar cualquier conexión natural o predefinida entre cuerpos de sus propias características o las capacidades adscritas o atribuidas a ellos. Esto ofrece la experiencia de estar sin destino, pero siendo capaz de encontrar o formar - no elegir- su propio destino o forma.

2) También suspende el orden funcional y el uso de las cosas - palabras, acciones- al hacer públicos - conocimiento y prácticas y al ponerlos sobre la mesa-, mientras los saca del círculo del consumo, al alcance de la mano en una forma dramatizada - lo que también podría llamarse profanación-, por ejemplo, convertir algo del mundo en materia escolar, en materia pública. En ese sentido, la escuela dice - sin decir-que el mundo no le pertenece a nadie.

3) Cumple la crucial función de formar atención confiando en un doble amor, tanto para el mundo como para las nuevas generaciones, y en las prácticas disciplinarias, con el fin de hacer posible la atención. Esta importancia de la atención se puede formular de forma diferente: la escuela no solo da a conocer las cosas, sino que también expone a los estudiantes a estas cosas y les da a estas cosas autoridad o presencia, lo que las hace entrar en nuestra compañía, en el sentido más estricto. En la escuela - si funciona como escuela, es decir, si la reunión se convierte en un evento- los estudiantes están expuestos al mundo; o más precisamente, alguien se convierte en un estudiante en relación con esta divulgación mundial. Piensen en el mundo de las matemáticas o la biología, o el de los números y de la naturaleza. La escuela no se trata solamente de transmitir conocimiento acerca de esos mundos, sino de ofrecerles a las nuevas generaciones la posibilidad de relacionarse y apegarse a estos mundos, es decir, preocuparse. Lo que precisamente pasa en la escuela cuando funciona como una escuela es que a veces se vuelve real y llega a existir en sí misma. Las aves se vuelven aves reales, la madera se vuelve madera real, palabras en español se vuelven palabras reales en español... Esto literalmente significa que algo - palabras en español, una pieza de madera, aves... - se hace parte de nuestro mundo y en las formas del mundo. Cuando algo se vuelve parte del mundo no 
significa que se vuelva un objeto de conocimiento - algo que sabemos sobre el mundo-, sino se vuelve parte del mundo en o por el cual nosotros estamos inmediatamente involucrados, atados y, por lo tanto, algo que se convierte en un interés. Podríamos decir que ya no es más un objeto -inanimado-, sino que es una cosa con vida. Alguien que se interesa en las matemáticas se está apegando al mundo de los números; empieza a pertenecerle a ese mundo. Para él o ella, el mundo de las matemáticas se vuelve un tema de preocupación. Esto es lo que pasa en la película El hijo (2002), de los cineastas belgas, los hermanos Dardenne. Nos confronta con Olivier, un profesor muy ordinario que triunfa - este éxito viene a través de las tecnologías y la ética- al despertar un interés por la carpintería en uno de sus estudiantes con problemas llamado Francis, un delincuente juvenil condenado de asesinato que viene a aprender una ocupación con la esperanza de volver a la sociedad algún día. Vemos cómo la madera se vuelve madera real para este estudiante y no simplemente algo para hacer gabinetes o sillas, para la chimenea, o para que sea una ocupación que "lo lleve devuelta a la sociedad" - el proyecto de reintegración-. La madera se vuelve indiferente a su lugar "propio" - es parte de un proyecto o una intención-; se vuelve verdadera madera en sí misma y algo de lo que Francis se ocupa. Por lo tanto, se convierte en parte del mundo de este estudiante, en sentido estricto. Empieza a pertenecerle a su mundo; lo interesa y lo mantiene ocupado. Es algo que empieza a formarlo. Le acarrea cambios. Cambia la forma en la que percibe su vida y el mundo. Le permite empezar de nuevo con el mundo. Ahora la madera no solo pertenece a -tiene un lugar en - su mundo, sino que él empieza a pertenecer al mundo de la madera.

Es importante enfatizar que la escuela posibilita una experiencia de existencia, como ser capaz de empezar con algo, algo que empieza a importar - requiere cuidado, atención-. Esta experiencia es compartida. Un colectivo de experiencias personales significa tener algo en común, ya que está puesto sobre la mesa. Por supuesto, hay diferencias entre la gente, pero se suspenden cuando la escuela sucede, es decir, cuando algo se vuelve interesante, cuando es atendido y se crea la intención. En este contexto, vale la pena mencionar un comentario del psiquiatra belga Mark Van Bellingen 
en un periódico (4/11/2017), al comentar sobre una pandilla exclusivamente de chicas que aterrorizaba a la gente que entraba y salía de la estación del tren de Brujas, Bélgica. Los ataques eran violentos. "Miren a esas chicas. Se les prohíbe ir a la escuela o ellas mismas la desprecian y la rechazan". Las amistades solo existen al reconocer la miseria de los demás. Estas relaciones no empiezan de un interés compartido, sino de una necesidad compartida. En la escuela, por el contrario, la reunión no empieza de una falta o una necesidad, sino de un interés.

En lo que concierne a la escolástica sobre abrir el mundo, la atención -y no tanto la motivación- es el tema crucial. La escuela, con sus profesores, disciplina escolar y arquitectura -si opera como escuela, como forma pedagógica-, les infunde atención hacia el mundo a las nuevas generaciones: las cosas empiezan a hablar(nos). Se trata del momento mágico cuando algo afuera de nosotros nos invita a considerar - pero también a ser respetuosos, a preocuparnos, a ser reflexivos-. En ese mágico momento algo deja de ser de repente una herramienta o un recurso y se convierte en algo real que nos hace pensar, pero también nos hace estudiar y practicar. Es un evento, en el sentido estricto de la palabra; un asunto empieza a cobrar importancia. Una prueba matemática, una novela, un virus, un cromosoma, un bloque de madera o un motor: todas esas cosas se vuelven significativas e interesantes. Este es el evento mágico de la escuela, el movere - el movimiento real-, el cual no se remonta a una decisión individual, elección o motivación. Si bien la motivación es una especie de asunto personal y mental, el interés es siempre algo fuera de nosotros, algo que nos toca y nos mueve a estudiar, a pensar y a practicar. Nos lleva fuera de nosotros mismos. La escuela se vuelve un tiempo/espacio del inter-esse, de aquel que es compartido entre nosotros, el mundo en sí mismo. En ese momento, los estudiantes no son individuos con necesidades específicas que escogieron dónde quieren invertir su tiempo y energía; están expuestos al mundo e invitados a interesarse en él. Sin la presencia de un mundo, no hay interés ni intención.

El arte de hacer escuela es, por ende, el arte de la magia, la cual es el arte -emplear técnicas, artefactos, es decir, tecnología y un ethos particular-de hacer que algo empiece a hablar. Parafraseando las palabras de Isabel Stengers, se pretende organizar un modo 
de reunión y unidad, cuyo logro es que el yo, como un sujeto, ya no debe pertenecerle a nadie más que a sí mismo, quien piensa y siente. Esto no es porque uno se sienta abrumado, sino porque la reunión se hace presente - esto es lo que se denomina magia-. Es algo que transforma la relación y hace que nos conectemos y sintamos comprometidos - lo que podríamos llamar pertenecer-. Se da cuenta de una pertenencia; nos conectamos. La presencia no nos está diciendo qué hacer, sino que se convierte en una causa que nos apega y requiere buscar y explorar los medios apropiados, los caminos correctos para lidiar con esto, lo que también es vivir con esto. De ahí que el estudiante no es quien está en el centro. No es quien pregunta lo que ella puede hacer con esto, sino a la inversa. Las obligaciones se derivan de relaciones, y las relaciones son una causa para sentir y pensar, ser capaz y volverse capaz. La causa obliga, pero el cómo responder no está predefinido, sino que estamos retados a buscarlo cuando estamos expuestos - eso significa que son atentos-. Algo adquiere autoridad. Esto significa que la dirección cambia. No es el estudiante o sus necesidades o proyectos los que ofrecen el punto de partida, sino, por ejemplo, el lenguaje o las matemáticas son los que ofrecen la medida y obligan -obligan a hacerlo bien, lo que no es lo mismo que eficiente y efectivo-. La escuela es el nombre para un medio -y un ambiente- formado por prácticas y arquitecturas - no solamente un edificio- y por tecnologías herramientas y ethos- que no contienen técnicas de producción, sino técnicas de fomento y desafío (Stengers, 2013). Fomentar es potenciar algo para hablar - para que estemos atentos-. El docente es un portavoz - para el mundo-. Su voz es una tecnología crucial para hacer al mundo hablar. Desafiar es obligar, lo cual materializa la postura de Stengers de que nosotros - humanos- no estamos solamente en el mundo. Existen también, en sentido estricto, virus, fantasmas, ideas, animales, paisajes... y el asunto es cómo vivir con ellos. La escuela no se trata de elecciones y necesidades, tampoco de desarrollo, motivación o intención, sino de atención y encuentro. La escuela traduce el mensaje: bienvenidos a este nuestro mundo, el cual se les ofrece - para estudiar, hacer ejercicio, tiempo libre para encontrar su camino, intentar y errar-, pero también del cual hay que cuidar y renovar, ya que la escuela no es solo sobre ti, sino sobre el mundo al que pertenecemos.

Dado que se convierte en presente - tiempo libre-, la escuela es 
crucial. Sugeriré algunos elementos relacionados con la tecnología y el espíritu. De hecho, no solo es importante que la materia se convierta en materia escolar y que los jóvenes se conviertan en alumnos o estudiantes (Masschelein, Simons \& Larrosa, 2019), sino también que los profesores se conviertan en maestros de escuela. Volverse un maestro de escuela significa, por ejemplo, que tiene que dirigirse a un colectivo de estudiantes, lo que lo obliga a hablar en público y significa estar inactivo, es decir, no productivo - carpintero que se convierte en un maestro de escuela enseñando carpintería, no es más un carpintero "real", en el sentido de que no tiene que vivir de su carpintería-. El niño de escuela, diferente del aprendiz, se enfrenta a maestros que se ganan la vida enseñando. La carpintería se convierte por lo tanto en carpintería por el bien de la carpintería.

El maestro de escuela personifica un cierto conocimiento tema-y arte, pero también sabe sobre el arte de hacer escuelay ayuda a revelar el mundo, a compartir el mundo, mientras atrae atención e interés que se distingue de su utilidad inmediata, por lo que nos saca de nosotros mismos hacia la compañía con/del mundo. El rol del lenguaje y de la voz es muy importante aquí, precisamente porque es usada para presentarles el mundo a los estudiantes. Se quiere nombrar - algo del- mundo sin encerrarlo, por lo tanto, el lenguaje tiene algo de lenguaje abstracto. Pero el lenguaje debería también invitar, tener la fuerza de recolectar y no imponer expectativas como el lenguaje poético, lenguaje para invitar, inspirar-, haciendo que los estudiantes hablen - sin silenciarlos-, dándoles palabras -sin imponer definiciones cerradas-.

Lo que la voz puede hacer, en tanto que no se trata de celebrar el conocimiento o arte en sí de alguien, es fortalecer lo que está ahí para ver y oír, incrementar su realidad, aumentarla, darle autoridad. Una voz no es solamente comunicar/dar significado, también es en sí misma una fuerza - frecuentemente relacionada con su tono-. Una voz que testifica que lo que se ofrece está presente también para quien habla es una voz que testifica algo fuera de sí misma y, por lo tanto, podría cerrar la reflexión y su entusiasmo. No se trata de persuadir - convencer - o de discutir, sino de abrir el mundo para todo el mundo - discurso pedagógico-. La fuerza educativa de la voz del maestro de escuela contribuye a hacer algo presente como realidad compartida y, por lo tanto, da cuenta de una presencia o atención común por algo. En ese momento existe también la 
experiencia de pertenecer, de ser parte de una reunión, de una unidad -comunidad, si se prefiere- que se reúne alrededor de algo -como en la acotación de un psiquiatra-. Por favor, no lo entiendan en el sentido de espectáculo y drama, sino en el sentido de que se testifica la atención, el estar presente. Este aumento de poder no es una competencia que deba ser aprendida en relación con un estilo de vida. Quizás, precisamente en tiempos de la pantalla y comunicación a distancia nos volvemos conscientes de la importancia de la voz para darles autoridad a los mundos, como en el ejemplo del mundo de las aves, con el cual comencé mi presentación. Esto me lleva a la última parte.

Como ya lo había mencionado, la escuela como forma pedagógica traduce el mensaje "bienvenidos aquí, a nuestro mundo". Hoy día, nuestras instituciones educativas parecen traducir otro mensaje. En el 2006, la revista Time escogió "Tú" como la persona del año. En su portada podíamos leer: "Tú, sí, tú controlas la era de la información. Bienvenido a tu mundo". Y pienso de hecho que nuestras instituciones educativas están cada vez más transformadas en ambientes de aprendizaje que incluyen formas de aprendizaje personalizadas, centralidad en el estudiante, orientación por la competencia, inclusión, talento y diagnósticos de necesidades, estrategias de motivación, énfasis en las decisiones..., lo que no solo traduce y transmite este mensaje incluso más fuerte, sino que también lo pone en práctica a través de todo tipo de tecnologías, no de formación, sino de personalización y elaboración de perfiles (Simons \& Masschelein, 2019). Esta es la desescolarización de nuestras instituciones educativas.

Hoy la agenda de la innovación desde los legisladores y los expertos en educación, por "darle al estudiante el escenario central" o "liberar al estudiante", critica la estructura disciplinar de la escuela, pero al mismo tiempo promueve una nueva institucionalización de la enseñanza y el aprendizaje, incluyendo una nueva arquitectura: la arquitectura del ambiente de aprendizaje, que opera a través de perfiles, realimentación y monitoreo y se ha traducido en una "producción de resultados de aprendizaje" relacionados con la preocupación por la eficiencia, la eficacia y la visibilidad permanente - perfilar-que transforma todo el tiempo en tiempo de producción. Esta es la figura del estudiante personalizado que parece habitar los ambientes de aprendizaje de hoy día. Relacionaré brevemente 
esto con el asunto de lo digital. Cuando yo digo digital, me refiero a tres cosas: la pantalla - tiene una fuerza enorme para atraer la atención-, el internet - tiene una fuerza enorme de profanación y de hacer algo público-y el algoritmo - ofrece la posibilidad de tener todo en cuenta y está transformando todo en cálculo y dirección de forma efectiva, eficiente y personalizada: computador personal, búsqueda personal, perfil personal; lo que implica visibilidad permanente y la imposibilidad de errar-. De cierta forma, algunas de las operaciones de la escuela como forma pedagógica están fuertemente presentes - atención y profanación-, pero parece que ellas contribuyen a la capitalización y a la irrealidad - no fricción, no presente o realidad-; además a la dependencia del estudiante -y del profesor-. Sin embargo, el estudiante está en constante "necesidad de reconocimiento" y depende de realimentación permanente en su perfil personalizado o su puesta en escena para tener una experiencia de existencia -de ser real: tú no existes sin un perfil, red-. Los intentos actuales de "liberar al estudiante" y de "darle el escenario central" son quizás, ante todo, parte de una larga historia de tratar de crear niños a nuestra propia imagen.

Para ponerlo un poco de manera provocadora: si queremos revaluar la pertenencia -o presencia, la cual implica también algún tipo de libertad, o emancipación- quizás no necesitemos tantas teorías psicológicas sobre motivación y desarrollo de competencias, pero tal vez sí necesitemos teorías educativas que sustenten la reivindicación y la re-invención tecnológica de la escuela como forma pedagógica - resistir su transformación en un ambiente de aprendizaje personalizado-. En un tiempo de desescolarización, donde los ambientes de aprendizaje invocan y están basados en la experiencia del ser vistos y reconocidos - perfilar en un escenario-, vale la pena defender la reescolarización de nuestras instituciones educativas. Esta reescolarización no se basa en volver o restaurar la "vieja escuela", sino en reinventar la escuela. Inspirado por las ideas sobre el trabajo y la atención de Simone Weil, yo sugeriría que vale la pena reinventar la escuela como forma pedagógica, no como un ambiente de aprendizaje - un espacio productivo-, sino más bien como un lugar de trabajo colectivo, donde se enfatice en el trabajo, no en el aprendizaje, como una acción atenta y reflexiva, para crear un lugar - un espacio que tiene importancia y no un escenario o un ambiente-, como condición para generar "tiempo libre"-separado 
de la producción y que "permanezca invisible"-, para generar un sentido de apego - pertenencia o estar en contacto- con el mundo, algo más que hable y te separe de ti mismo, que cree un inter-esse y que es en verdad lo que te da tiempo. El asunto es cómo hacer del mundo algo real, hacerlo presente y descartar los escudos, las pantallas, los espejos y los escenarios que parecen habernos encerrado cada vez más en autorreflexiones e interpretaciones, en entornos interminables de puntos de vista, perspectivas, opiniones, perfiles personales y actuaciones. No se trata de valores, sino de la postura, es decir, la forma en que nos relacionamos con el mundo para que se abra como un espacio existencial -de pertenencia-.

\section{Referencias}

Arendt, H. (2016). Entre el pasado y el futuro (Trad. A. Poljak). Barcelona: Península.

Dewey, J. (2004). La opinión pública y sus problemas. Madrid: Morata.

Larrosa, J. (Ed.). (2018). Elogio de la escuela. Buenos Aires: Miño y Dávila.

Masschelein, J., \& Simons, M. (2014). Defensa de la escuela. Una cuestión pública. Buenos Aires: Niño y Dávila.

Masschelein, J., \& Simons, M. (2019). Bringing more «school» into our educational institutions. Reclaiming school as pedagogic form. En A. Bikner-Ahsbahs (Ed.), Unterrichtsentwicklung macht Schule Forschung und Innovation im Fachunterricht (pp. 11-30). Verlag: Springer.

Masschelein, J., Simons, M., \& Larrosa, J. (2019). The matter with/of school. Storylines of the scholastic fable. En R. Mayer, A. Schäfer, \& S. Wittig (Eds.), Jacques Rancière: Pädagogische Lektüren (pp. 135153). Springer.

Platón. (1992). República. En Platón, Diálogos: Vol. IV. Madrid: Gredos.

Simons, M., \& Masschelein, J. (2019). Should the learner be the center of education? Limits of personalization. Leuven ECS Publisher.

Stengers, I. (2013). Au temps des catastrophes. Résister à la barbarie qui vient. 